\title{
A Model of the Eurosystem's Operational Framework and the Euro Overnight Interbank Market*
}

\author{
Achim Hauck $^{\dagger} \quad$ Ulrike Neyer ${ }^{\ddagger}$
}

August 9, 2016

\begin{abstract}
This paper develops a theoretical model which replicates main institutional features of the euro overnight interbank market and the Eurosystem's operational framework which has been in place since September 2008. Main ingredients of the model are frictions in form of participation costs in the interbank market, a refinancing operation with unlimited liquidity supply and two standing facilities offered by the central bank. The model can explain several stylized facts observed during the financial crisis as the decline in interbank borrowing and the interbank rate, the increased borrowing from the Eurosystem and the strong recourse to its deposit facility. Furthermore, we discuss some policy implications.
\end{abstract}

JEL classification: E52, E58, G01, G21

Keywords: Liquidity; Monetary Policy Implementation; Interbank Market; Financial Crisis

${ }^{*}$ We thank Diemo Dietrich, Martin Mandler, Dieter Nautz, Rüdiger Pohl, Franz Seitz, Birgit Uhlenbrock, the participants of the 2010 conference of the European Finance Association, the European Financial Management Association, the Verein für Socialpolitik and the Swiss Society of Economics and Statistics, the participants of the 2012 conference of the European Economic Association, and seminar participants at the European Central Bank, Deutsche Bundesbank and Université Paris X Nanterre for helpful comments. All remaining errors and shortcomings are, of course, our own.

${ }^{\dagger}$ Corresponding Author: Heinrich-Heine-University Duesseldorf, Department of Economics, Universitaetsstrasse 1, 40225 Duesseldorf, Germany, Tel.: +49/(0)211/81-15342, Email: achim.hauck@uniduesseldorf.de, and University of Portsmouth, United Kingdom.

${ }^{\ddagger}$ Heinrich-Heine-University Duesseldorf, Department of Economics, Universitaetsstrasse 1, 40225 Duesseldorf, Germany, Tel.: +49/(0)211/81-11511, Email: ulrike.neyer@uni-duesseldorf.de. 


\section{Introduction}

The worldwide financial crisis, which broke out in August 2007, triggered severe turbulence in the euro area interbank markets. Particularly the collapse of Lehman Brothers in September 2008, the advent of the Greek sovereign debt crisis in December 2009, and the culmination of sovereign debt problems in several euro area countries in summer 2011 had a deep impact on these markets. During these periods, transaction volumes fell dramatically and the interest rate for overnight interbank lending, which is usually slightly above the Eurosystem's ${ }^{1}$ key policy rate, declined significantly below this rate. At the same time, aggregate borrowing of euro area commercial banks from the Eurosystem but also their use of the Eurosystem's deposit facility rose sharply.

This paper develops a theoretical model of an interbank market which captures the main institutional features of the euro area. The model shows that interbank market participation costs play a crucial role for explaining the stylized facts observed in the euro area. In addition, it allows to discuss some policy implications.

In our model, there is a commercial banking sector consisting of two types of banks. One type faces an uncertain liquidity deficit while the other type faces an uncertain liquidity surplus. At the aggregate level, the banking sector faces a net liquidity deficit which can only be covered by the central bank. The commercial banks can obtain unlimited liquidity from the central bank by borrowing against collateral in a standard refinancing operation or a lending facility. Moreover, the banks can place liquidity at the central bank by using a deposit facility. The interest rates on the refinancing operation and the two facilities are set by the central bank. The commercial banks can also lend and borrow liquidity in an interbank market to balance their individual liquidity needs. This market is characterized by frictions. Commercial banks that borrow in the interbank market are

\footnotetext{
${ }^{1}$ The term "Eurosystem" stands for the institution which is responsible for monetary policy in the euro area, namely the ECB and the national central banks in the euro area. For the sake of simplicity, the terms "ECB" and "Eurosystem" are used interchangeably throughout this paper.
} 
confronted with interbank market participation costs which reflect signalling costs, search costs, or reputational costs.

The model shows that the banks' optimal borrowing in the central bank's refinancing operation, their activities in the interbank market and their recourse to the central bank's facilities depend on these participation costs. If participation costs are relatively low, the aggregate liquidity demand in the refinancing operation will correspond to the net liquidity deficit of the banking sector. Then, the commercial banks will use the interbank market to balance their individual liquidity needs. In this case, the facilities offered by the central bank remain unused. However, if borrowers' interbank market participation costs exceed a critical level, it will become more attractive for deficit banks to cover a higher part of their liquidity needs in the central bank's refinancing operation instead of using the interbank market. In this situation, the crucial point is that aggregate borrowing from the central bank will exceed the aggregate liquidity needs. There will be excess liquidity in the banking sector. As a consequence, the interbank market rate as well as the transaction volume in the interbank market will decrease and the surplus banks are forced to place liquidity in the central bank's deposit facility. Thus, the central bank will replace the interbank market by assuming an intermediary function between liquidity surplus and liquidity deficit banks.

Often it is argued that the observed massive recourse to the central bank's deposit facility during the financial crisis reflects excess liquidity held for precautionary motives (see, for example, Trichet, 2009). Our model shows that precautionary motives are unlikely to be the sole explanation for this observation because hoarding liquidity in the deposit facility as a precaution is rather expensive compared to using the credit facility if necessary. Considering explicitly the institutional background in the euro area, the model provides a further explanation for the large amounts of liquidity placed in the deposit facility. Due to a significant increase in interbank market participation costs during the financial crisis, the central bank has acted as an intermediary between surplus and deficit banks. 
The Eurosystem aims at reversing its intermediary function and at reactivating interbank market transactions (Smaghi, 2008). Compared to a centralized interbank market, in which the central bank assumes the role of an intermediary, a decentralized interbank market is viewed to improve the efficiency of the liquidity allocation for three main reasons. ${ }^{2}$ First, interbank markets are characterized by informational asymmetries and commercial banks are in a better situation to gather and process information about their peers than the central bank. Therefore, decentralized interbank markets ensure that the allocation process is based on more information. ${ }^{3}$ Second, in a centralized interbank market the banks' incentive to monitor their peers is reduced, which weakens market discipline. Third, as credit transactions with the central bank have to be based on adequate collateral, a decentralized interbank market may contribute to a more efficient liquidity allocation when banks may lack sufficient adequate collateral to cover their liquidity needs by borrowing directly from the central bank. ${ }^{4}$

According to our model, the obvious way to reverse the intermediary function assumed by the ECB is to reduce interbank market participation costs. However, this cannot be accomplished by the Eurosystem. In general, it cannot reduce uncertainties about the soundness of commercial banks. Our model shows that a central bank can reactivate the interbank market by making its transactions with the banking sector less attractive. This could be achieved, for example, by tightening the requirements for collateral or by decreasing the rate on the deposit facility. However, as long as transactions in the

\footnotetext{
${ }^{2} \mathrm{~A}$ detailed discussion of the costs and benefits of centralized and decentralized interbank markets can be found in Bräuning and Fecht (2012).

${ }^{3}$ For theoretical papers dealing with asymmetric information in the interbank market see, for example, Freixas and Holthausen (2005); Freixas and Jorge (2008); Heider, Hoerova, and Holthausen (2009). For empirical evidence of the importance of asymmetric information in the interbank market see Afonso, Kovner, and Schoar (2011). Bräuning and Fecht (2012) discuss the importance of peer monitoring in interbank markets. In an empirical analysis of the German interbank market, they show that the conditions in that market reflect private information generated by peer monitoring and that this information matters for the liquidity allocation in the banking sector. In this context, relationship lending plays a crucial role in the interbank market. In a similar analysis Cocco, Gomes, and Martins (2009) emphasize the importance of lending relations for the Portuguese interbank market.

${ }^{4}$ In this context, Neyer and Wiemers (2004) show theoretically that if banks differ in their collateral costs, an interbank market will emerge as banks with lower collateral costs will borrow more liquidity from the central bank than necessary to cover their own liquidity needs to lend the excess liquidity via the interbank market to those banks which have to cope with higher collateral costs.
} 
interbank market are relatively costly, these measures will increase banks' liquidity costs. In an economic and financial crisis, this increase usually conflicts with a central bank's aim to maintain or reestablish financial stability.

The rest of the paper is organized as follows. In section 2, we give a brief survey on related literature. Section 3 provides the institutional background. Section 4 describes the stylized facts to be explained by our theoretical model which is presented in section 5 . In section 6 , we discuss the results and the policy implications. The last section summarizes the paper.

\section{Related Literature}

Our paper relates to the theoretical literature on the implementation of monetary policy in the euro area. A first strand of this literature concentrates on over- and underbidding incentives of commercial banks in the Eurosystem's main refinancing operation under different tender procedures (see, for example, Ewerhart, 2002; Nautz and Oechssler, 2003; Ayuso and Repullo, 2003; Bindseil, 2005; Ewerhart, Cassola, and Valla, 2010, 2012). ${ }^{5}$ These contributions either abstract from the existence of an interbank market or assume that it is frictionless. In contrast to this, the second strand of the literature emphasizes the relevance of frictions in interbank markets. Nyborg and Strebulaev $(2001,2004)$ show that market power in interbank markets may lead to short squeezes, which influence the commercial bank's bidding behavior in the central bank's refinancing operation. ${ }^{6}$ Neyer and Wiemers (2004) argue that also transaction costs in the interbank market cause a positive spread between the interbank rate and the rate on the refinancing operation. ${ }^{7}$

\footnotetext{
${ }^{5}$ See also Shino (2012), who studies the bidding incentives of commercial banks against the background of the tender operations conducted by the Bank of Japan. Empirical evidence on the behavior of euro area commercial banks before the financial crisis can be found in Breitung and Nautz (2001), Ayuso and Repullo (2001), Nyborg, Bindseil, and Strebulaev (2002) and Nautz and Oechssler (2006).

${ }^{6}$ Linzert, Nautz, and Breitung (2006), Bindseil, Nyborg, and Strebulaev (2009) and Fecht, Nyborg, and Rocholl (2010) provide empirical support for the relevance of short squeezes.

${ }^{7}$ There is ample empirical evidence for a positive spread between the interbank rate and the rate on the refinancing operation before the outburst of the financial crisis (see, for example, Ejerskov, Moss, and Stracca, 2003; Bruno, Ordine, and Scalia, 2005; Hassler and Nautz, 2008; Linzert and Schmidt, 2011).
} 
Neyer (2009) discusses the implications of transaction costs in the interbank market for commercial banks' reserve holdings under different remuneration schemes of reserves. In these papers, the Eurosystem's standing facilities, which have turned out to be important during the financial crisis, typically play no role.

We add to the literature on the implementation of monetary policy in the euro area by developing a model of an interbank market with frictions, which considers explicitly the institutional framework in the euro area, including the two standing facilities offered by the Eurosystem. ${ }^{8}$

In addition, our paper relates to the literature that analyzes the liquidity management of credit institutions and central banks during the financial crisis. Lenza, Pill, and Reichlin (2010) describe in detail the conduct monetary policy of the ECB, the Fed and the Bank of England. Borio and Disyatat (2010) classify the different unconventional measures undertaken by central banks during the crisis and discuss their consequences for the transmission channel of monetary policy and the challenges these measures raise for policy makers, for example with regard to the relationship to fiscal policy and the independency of the central bank. Eisenschmidt, Hirsch, and Linzert (2009) empirically analyze the banks' bidding behavior in the ECB's main refinancing operations during the financial crisis until October 2008. Cassola and Huetl (2010) also look at this first phase of the financial crisis. They investigate the consequences of the crisis on the rate and the transaction volume in the overnight interbank market (see also Soares and Rodrigues, 2010; Angelini, Nobili, and Picillo, 2011; Brunetti, di Filippo, and Harris, 2011). Eisenschmidt and Tapking (2009) analyze the evolution of liquidity risk premia in unsecured interbank markets. From a theoretical perspective, Allen, Carletti, and Gale (2009) discuss central bank measures to reduce the volatility of the interbank rate. Bruche and Suarez (2010) and Heider, Hoerova, and Holthausen (2009) show that asymmetric information and counterparty risk

\footnotetext{
${ }^{8}$ For papers dealing with the liquidity management of U.S. credit institutions, the operational framework of the Federal Reserve System and the consequences for the U.S. federal funds market. See, for example, Ho and Saunders (1985), Hamilton (1996), Clouse and Dow (1999, 2002), Furfine (2000), and Bartolini, Bertola, and Prati (2001, 2002).
} 
can lead to a decline in the transaction volume in the interbank market. ${ }^{9}$ Literature on banks' liquidity management during the financial crisis also deals with liquidity hoarding for precautionary reasons: Allen, Carletti, and Gale (2009) distinguish between two types of uncertainty with respect to the banks' liquidity needs: idiosyncratic uncertainty and aggregate uncertainty. They show that if the latter is sufficiently large compared to the former, it will be efficient for commercial banks to hoard liquidity instead of trading it in the interbank market. Caballero and Krishnamurthy (2008) show that if aggregate liquidity is limited and if there is Knightian uncertainty (immeasurable risk), banks will start to hoard liquidity. Ashcraft, McAndrews, and Skeie (2011) develop a model in which it is rational for banks to hold precautionary liquidity which face credit constraints and limited participation in the interbank market. Empirical analyses dealing with precautionary motives of holding excess reserves provide mixed results. Acharya and Merrouche (2009) and Ashcraft, McAndrews, and Skeie (2011) find evidence for a precautionary hoarding of liquidity in the UK and in the US for 2007 and 2008. However, referring to the US overnight interbank market from April 2008 until February 2009, Afonso, Kovner, and Schoar (2011) find no evidence for liquidity hoarding.

Our paper adds to this literature by providing a simultaneous explanation for the strongly increased demand for central bank liquidity, the significant use of the deposit facility, the decrease of the interbank market transaction volume, and the systematic decrease of the interbank market rate below the key policy rate in the euro area. Furthermore, respective policy implications are drawn.

\section{Institutional Background}

Deposits that banks hold on their accounts with the central bank plus the currency they hold are the reserves of the banking sector. In the euro area, the banking sector's needs for reserves arise from minimum reserve requirements and autonomous liquidity factors,

\footnotetext{
${ }^{9}$ The role of asymmetric information for potential freezes in the interbank market is also explored in Freixas and Holthausen (2005), Freixas and Jorge (2008) and Angelini, Nobili, and Picillo (2011).
} 
as banknotes in circulation. Needs for reserves can only be satisfied by the Eurosystem. It has monopoly power over the creation of reserves. This allows the Eurosystem to steer the interest rate in the interbank market for reserves, which is its operating target.

Important instruments for providing/absorbing reserves are the main refinancing operations (MROs), longer-term refinancing operations, fine-tuning operations and two standing facilities. The MROs, the longer-term refinancing operations and the fine-tuning operations belong to the open market operations. The MROs are credit operations. They have a maturity of one week and are conducted weekly as either a fixed or a variable rate tender. For each MRO, the ECB calculates a benchmark allotment, which reflects the banking sector's liquidity needs during the maturity of the MRO if the reserve requirements are fulfilled smoothly over the reserve maintenance period. In "normal" times, bids in the MRO will be rationed if total bids exceed the benchmark allotment. A further source of reserves for the banking sector are longer-term refinancing operations. In "normal" times they are conducted once a month and have a maturity of three months. Fine-tuning operations are non-standardized instruments to provide or absorb liquidity. Concerning the two standing facilities one has to distinguish between a credit facility and a deposit facility. Both have an overnight maturity. On the initiative of the banks, the credit facility provides liquidity, whereas the deposit facility absorbs liquidity. The interest rates on these facilities usually form a symmetric corridor around the MRO-rate. Credit operations with the Eurosystem have to be based on adequate collateral. Assets eligible as collateral must fulfil certain criteria defined by the Eurosystem. ${ }^{10}$

During the financial crisis, which broke out in August 2007, times were no longer "normal" and the ECB adopted a couple of non-standard-measures comprising the following six building blocks. ${ }^{11}$ (1) The Eurosystem fully satisfied the banks' demand for liquidity

\footnotetext{
${ }^{10}$ For a detailed description of the Eurosystem's monetary policy instruments including its minimum reserve system and for information on the collateral framework see European Central Bank (2011b). For a detailed description of the Eurosystem's liquidity management see European Central Bank (2002).

${ }^{11}$ For a brief survey see, for example, Trichet (2009). For a detailed description of the implementation of monetary policy by the Eurosystem in response to the financial crisis see European Central Bank
} 
although it exceeded the Eurosystem's benchmark allotment by far. (2) The list of assets eligible for use as collateral was expanded. (3) The range of maturities of longer-term refinancing operations was expanded up to one year. (4) The Eurosystem provided liquidity in foreign currencies. (5) The Eurosystem started to purchase euro-denominated covered bonds. (6) In May 2010, a Securities Market Programme was introduced which allows the ECB to intervene in securities markets.

In the interbank market for reserves, banks reallocate the reserves originally provided by the central bank. One reason for this reallocation is that usually, the shortest frequency at which the Eurosystem provides reserves to the banking sector is one week, namely through its MROs. While the needs for reserves of the banking sector as a whole may not change significantly within one week, the needs for reserves of individual banks usually fluctuate daily. Another reason why banks exchange reserves on the interbank market is that not all banks borrow directly from the central bank. Instead, there are banks which prefer to cover their needs for reserves exclusively in the interbank market. ${ }^{12}$

\section{Stylized Facts}

The collapse of Lehman Brothers in September 2008 marked a turning point for the euro area banking sector. This becomes evident from Figure 1. Its upper panel presents the Eurosystem's lending to the euro area banking system via its open market operations, the banking sector's needs for reserves arising from autonomous factors and the reserve requirement, and the transaction volume in the interbank market for overnight loans (EONIA volume). The lower panel of the figure shows the banking sector's recourse to the facilities offered by the Eurosystem.

(2009, 2010, 2011a). Details on the Securities Market Programme can also be found in González-Páramo (2010).

${ }^{12}$ In the euro area, more than 1.700 banks are eligible to participate in the MROs. However, less than 500 banks actually take part in these operations (European Central Bank, 2007, p. 89). For a respective theoretical analysis see Neyer and Wiemers (2004). 


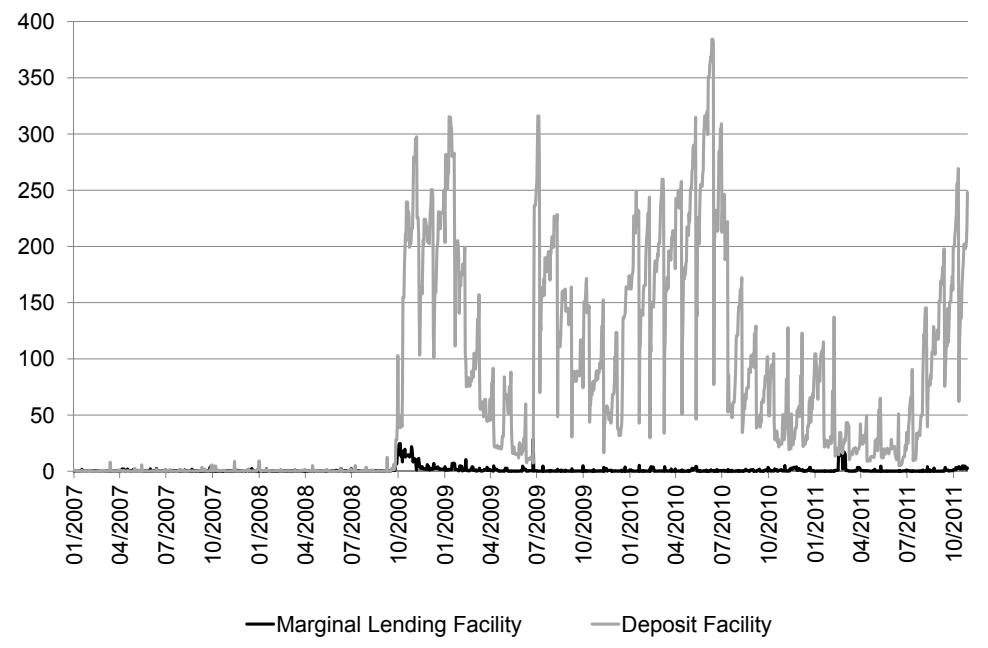

Figure 1: Lending and Borrowing of Reserves in the Euro Area (EUR Billions). Data: ECB. ${ }^{*}$ Exclusive Securities Markets Programme, ${ }^{*}$ Net Liquidity Effect from Autonomous Factors and Securities Markets Programme, ${ }^{* * *} 20$ day moving average.

The Figure reveals that until the outbreak of the crisis in the summer 2007, the Eurosystem's open market provision of reserves matched the banking sector's needs to cope with autonomous liquidity factors and to fulfill the reserve requirement. The grey and the black line in the upper panel almost coincide. Also during the first phase of the financial crisis, from July 2007 until September 2008, on average over a reserve maintenance period, the Eurosystem's lending to the banking system was still equal to these liquidity needs. ${ }^{13}$ During this period, the transaction volume on the interbank market was relatively large and neither the deposit facility nor the lending facility played a significant role for the commercial banks in the euro area.

After the collapse of Lehman Brothers in September 2008, matters changed drastically. The banking sector's demand for reserves in the Eurosystem's open market operations increased strongly, exceeding by far the amount of liquidity needed to cope with autonomous factors and the reserve requirement. This increased demand was fully satisfied by the Eu-

\footnotetext{
${ }^{13}$ During the first phase of the financial crisis, the Eurosystem allowed the credit institutions to "frontload" required reserves. At the beginning of a reserve maintenance period ample liquidity was provided, while over the course of the maintenance period the liquidity supply was gradually adjusted downwards so that on average over a reserve maintenance period, the Eurosystem's lending was still equal to the banking sector's liquidity needs resulting from autonomous factors and the reserve requirement (European Central Bank, 2009).
} 


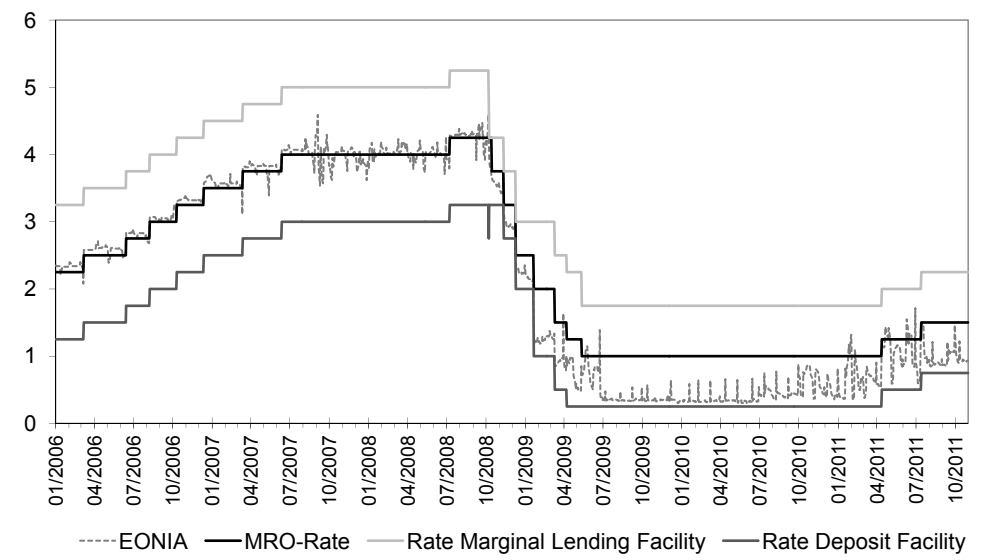

Figure 2: EONIA and Key ECB Interest Rates (Percentage). Data: Deutsche Bundesbank.

rosystem. Consequently, a gap emerged between the liquidity provided by the central bank and the banking sector's liquidity needs arising from autonomous factors and the reserve requirement. The massive liquidity supply by the Eurosystem came along with a systematic fall of the EONIA ${ }^{14}$ below the MRO-rate, close to the rate on the deposit facility (see Figure 2). ${ }^{15}$ Moreover, the transaction volume on the interbank market fell significantly and the euro area commercial banks allocated large amounts of liquidity to the deposit facility.

Figure 1 shows that the gap between the liquidity provision of the Eurosystem and the banking sector's liquidity needs arising from autonomous factors and the reserve requirement was particularly large during three periods: directly after the collapse of Lehman Brothers in September 2008, after the Greek sovereign debt crisis became apparent in December 2009, and after the sovereign debt crisis in several euro area countries intensified

\footnotetext{
${ }^{14}$ EONIA is the abbreviation for Euro Overnight Index Average. It is a market index computed as the weighted average of overnight unsecured lending transactions undertaken by a representative panel of banks. For more information on this reference rate see www.euribor.org.

${ }^{15}$ Note that usually, there is a positive spread between the interbank market rate and MRO-rate. For respective empirical analyses see, for example, Nyborg, Bindseil, and Strebulaev (2002), Ayuso and Repullo (2003), Ejerskov, Moss, and Stracca (2003), Nyborg, Bindseil, and Strebulaev (2002), and Neyer and Wiemers (2004). For a theoretical explanation see, for example, Ayuso and Repullo (2003) and Neyer and Wiemers (2004).
} 
in July 2011. Furthermore, the figure reveals that during these periods transactions in the interbank market (EONIA volume) fell even more and the recourse to the deposit facility increased strongly. However, with respect to the recourse to the marginal lending facility, a significant but, relatively to the recourse to the deposit facility, small increase can be observed only in the period directly after the insolvency of Lehman Brothers in September $2008 .^{16}$

\section{The Model}

\subsection{Framework}

We consider a one-period model which replicates the main institutional features of the market for reserves in the euro area. There is a large number of risk-neutral commercial banks facing uncertain autonomous liquidity needs. The banks can trade liquidity in an interbank market. Furthermore, a central bank provides and absorbs liquidity.

To obtain liquidity from the central bank, a commercial bank can participate in a refinancing operation and borrow the amount $R O \geq 0$ at the rate $i^{R O}$. It can also use a lending facility to borrow $L F \geq 0$ at the rate $i^{L F}$. Both credit operations with the central bank require adequate collateralization. Holding collateral $\operatorname{costs} \alpha>0$ per unit of liquidity. Consequently, borrowing $R O$ in the refinancing operation costs

$$
C^{R O}=\left(i^{R O}+\alpha\right) R O
$$

\footnotetext{
${ }^{16}$ Furthermore, the following aspects should be noted with respect to Figure 1. The increase in central bank lending in June 2009 goes in line with the first one-year maturity longer term refinancing operation conducted by the Eurosystem. This was one of its non-standard measures adopted during the crisis (see European Central Bank (2009) for details). The frequent downward spikes of the grey line are due to the liquidity absorbing fine tuning operations (collection of fixed term deposits) conducted by the ECB on the last day of a reserve maintenance period. The significant increase in the recourse to the marginal lending facility in the second half of February 2011 is due to "special effects arising from the restructuring of the Irish banking sector" (Deutsche Bundesbank, 2011, p. 26).
} 
while borrowing $L F$ in the lending facility costs

$$
C^{L F}=\left(i^{L F}+\alpha\right) L F
$$

The central bank also offers a deposit facility. A commercial bank can place liquidity $D F \geq 0$ in this facility at the rate $i^{D F}$ so that the costs of the deposit facility are

$$
C^{D F}=-i^{D F} D F
$$

The rates on the facilities form a symmetric corridor around the rate on the refinancing operation. We thus have $i^{R O}=0.5\left(i^{L F}+i^{D F}\right)$ with $i^{L F}>i^{R O}>i^{D F}$.

The commercial banks can borrow and lend liquidity in an interbank market. A bank's position in this market is $B$. If $B>0$, the bank will borrow the amount $B$ at the rate $i^{I B M}$. Conversely, $B<0$ indicates that the bank will lend the amount $|B|$ at this rate. Costs in the interbank market are

$$
C^{I B M}=i^{I B M} B+ \begin{cases}\frac{1}{2} \gamma B^{2} & \text { if } \quad B>0 \\ 0 & \text { if } \quad B \leq 0\end{cases}
$$

where the first term on the right hand side of (4) describes the interest costs/revenues and the second term describes a borrower's costs of participating in the interbank market. These participation costs are quadratic with $\gamma>0$. They can be justified on several grounds. For example, the participation costs of a borrower may reflect signalling costs as a consequence of asymmetric information. These costs occur because lenders are typically unwilling to expose themselves to any counterparty credit risk in the short-term interbank market. ${ }^{17}$ The higher is the intended borrowing volume, the more accurately a borrower

\footnotetext{
${ }^{17}$ To illustrate this, consider a bank with a liquidity surplus of 10 Million EUR and suppose that $i^{D F}=$ $0.25 \%$ and $i^{L F}=1.75 \%$, as it was the case in the euro area during the second half of 2009 and 2010 . By placing its liquidity in the deposit facility, the bank can earn approximately 70 EUR the next day. By lending overnight in the interbank market, it can earn at most 486 EUR because the interbank rate cannot exceed $i^{L F}$. Consequently, the bank will not lend in the interbank market if more than 416 EUR are at risk implying that lending must de facto be riskless. In the light of this argument, it is
} 
must signal his creditworthiness, which leads to a disproportionate increase in participation costs. ${ }^{18}$ In addition, the participation costs may also include costs of searching for banks with matching excess liquidity and costs resulting from the need to split large borrowing volumes into many small ones to work around credit lines. Participation costs may also reflect the fear of banks that borrowing large volumes in the interbank market might be harmful for their reputation. ${ }^{19}$

There are two types $j=d, s$ of commercial banks differing in their autonomous liquidity needs. Each type consists of a continuum of banks with unit mass. Type $d$ banks face an autonomous liquidity deficit $D>0$ whereas type $s$ banks face an autonomous surplus $S>0$. This distinction between deficit and surplus banks reflects the situation in the euro area. Brousseau and Manzanares (2009) argue that this is due to the banks' different business activities.

The magnitude of a bank's liquidity deficit/surplus is uncertain. With probability 0.5 , a deficit bank $d$ has a low deficit $D_{L}$. It has a high deficit $D_{H}>D_{L}$ with the same probability. A surplus bank $s$ has either a low surplus $S_{L}$ or a high surplus $S_{H}>S_{L}$ with probability 0.5. Individual liquidity needs are uncorrelated. Therefore, the law of large numbers implies that exactly half of the deficit banks will have a small deficit, while half of the surplus banks will have a small surplus. Consequently, the total deficit $D^{t}$, i.e. the deficit of all deficit banks, corresponds to a single bank's expected deficit, and the total

not surprising that empirically, an interest rate spread between the secured and unsecured overnight interbank market segment is virtually non-existent in the euro area.

${ }^{18}$ This argument builds on the huge literature on credit markets that focusses on adverse selection problems arising from informational asymmetries. This literature has been initiated by the seminal papers of Akerlof (1970) and Stiglitz and Weiss (1981). Signalling on credit markets was first introduced by Ross (1977) and Leland and Pyle (1977).

${ }^{19}$ Exogeneity of costs in the interbank market is a common assumption in the literature that focuses on the institutional design of interbank markets and central bank instruments (see, for example, Campbell, 1987; Bartolini, Bertola, and Prati, 2001). A derivation of the participation costs from first principles would heavily complicate our formal analysis without yielding much additional insight. 
surplus $S^{t}$, i.e. the surplus of all surplus banks, corresponds to a single bank's expected surplus:

$$
\begin{aligned}
D^{t} & :=\frac{1}{2} D_{L}+\frac{1}{2} D_{H}=E[D], \\
S^{t} & :=\frac{1}{2} S_{L}+\frac{1}{2} S_{H}=E[S] .
\end{aligned}
$$

The banking sector as a whole faces an aggregate deficit $\mathfrak{D}>0$, which can only be covered by the central bank. This implies

$$
\mathfrak{D}:=D^{t}-S^{t}>0
$$

Each bank of type $j=d, s$ aims to minimize its total expected liquidity costs, which depend on its transactions in the interbank market and its transactions with the central bank. The sequence of moves is as follows: At the beginning of the period, each bank decides on the amount $R O^{j}$ it borrows in the refinancing operation. The central bank pursues a full allotment policy by totally satisfying the banks' bids. After this, each bank learns its autonomous liquidity deficit $D_{k}$ or surplus $S_{k}$ with $k=L, H$. Simultaneously, the bank decides on its position $B_{k}^{j}$ in the interbank market, the amount $L F_{k}^{j}$ borrowed in the lending facility, and the amount $D F_{k}^{j}$ placed in the deposit facility.

\subsection{The Optimization Problem}

A deficit bank that aims to minimize its total expected liquidity costs faces a two-stage optimization problem that can be solved by backward induction. At the second stage, the bank decides on its interbank market transactions and its usage of the facilities taking 
the autonomous deficit $D_{k}$ and the amount $R O^{d}$ obtained in the refinancing operation as given. Therefore, at the second stage, the optimization problem reads as

$$
\begin{gathered}
C^{I B M}+C^{L F}+C^{D F}=: f\left(B_{k}^{d}, L F_{k}^{d}, D F_{k}^{d}\right) \rightarrow \min \\
\text { s.t. } R O^{d}+B_{k}^{d}+L F_{k}^{d}=D_{k}+D F_{k}^{d} .
\end{gathered}
$$

The left hand side of the budget constraint (9) reflects the possible sources of liquidity while the right hand side reflects the possible liquidity uses. At the first stage, the bank must decide on its borrowing in the refinancing operation without knowing its autonomous deficit $D_{k}$ yet. Indicating the computed optima of the second stage by the superscript opt, the optimization problem at the first stage is given by

$$
\begin{aligned}
C^{R O} & +\frac{1}{2} f\left(B_{L}^{d, o p t}, L F_{L}^{d, o p t}, D F_{L}^{d, o p t}\right) \\
& +\frac{1}{2} f\left(B_{H}^{d, o p t}, L F_{H}^{d, o p t}, D F_{H}^{d, o p t}\right)=: g\left(R O^{d}\right) \rightarrow \min .
\end{aligned}
$$

The first term reflects the costs of borrowing in the refinancing operation, the second (third) term reflects the minimum costs of interbank market transactions and using the facilities in case the bank faces a low (high) deficit.

In principle, a surplus bank faces the same two-stage optimization problem as a deficit bank. At the second stage, it must decide on its interbank market transactions and its usage of the facilities, so that the second stage problem is

$$
\begin{gathered}
C^{I B M}+C^{L F}+C^{D F}=: f\left(B_{k}^{s}, L F_{k}^{s}, D F_{k}^{s}\right) \rightarrow \min \\
\text { s.t. } R O^{s}+S_{k}+L F_{k}^{s}=D F_{k}^{s}-B_{k}^{s},
\end{gathered}
$$


where (12) reflects the budget constraint of the surplus bank. At the first stage, it must decide on its borrowing in the refinancing operation so that the first stage problem reads

$$
\begin{aligned}
C^{R O} & +\frac{1}{2} f\left(B_{L}^{s, o p t}, L F_{L}^{s, \text { opt }}, D F_{L}^{s, o p t}\right) \\
& +\frac{1}{2} f\left(B_{H}^{s, o p t}, L F_{H}^{s, o p t}, D F_{H}^{s, o p t}\right)=: g\left(R O^{s}\right) \rightarrow \min .
\end{aligned}
$$

\subsection{Results}

For the equilibrium of the model, the interbank market plays a crucial role. On the interbank market, one half of the deficit banks faces a low liquidity deficit $D_{L}$, while the other half faces a high deficit $D_{H}$. Their respective position in the interbank market is $B_{L}^{d, o p t}$ and $B_{H}^{d, o p t}$. Moreover, one half of the surplus banks has a low surplus $S_{L}$, the other half has a high surplus $S_{H}$. The position of low-surplus banks in the interbank market is $B_{L}^{s, o p t}$ while the position of high-surplus banks is $B_{H}^{s, o p t}$. As a consequence, market clearing in the interbank market requires

$$
\frac{1}{2}\left(B_{L}^{d, o p t}+B_{H}^{d, o p t}\right)+\frac{1}{2}\left(B_{L}^{s, o p t}+B_{H}^{s, o p t}\right)=0
$$

In conjunction with the optimization problem of the individual banks, the market clearing condition (14) leads to the equilibrium of the model. In this equilibrium, deficit banks will never supply liquidity in the interbank market while surplus banks will never demand liquidity, $B_{k}^{d, o p t} \geq 0$ and $B_{k}^{s, o p t} \leq 0$. Accordingly, we can define

$$
T:=\frac{1}{2}\left(B_{L}^{d, o p t}+B_{H}^{d, o p t}\right)=\frac{1}{2}\left(\left|B_{L}^{s, o p t}\right|+\left|B_{H}^{s, o p t}\right|\right)
$$

as the aggregate transaction volume in the interbank market.

Depending on the magnitude of the interbank market participation cost parameter $\gamma$, three distinct equilibrium types may arise. We will now discuss these types with the help of three propositions, in which the equilibrium variables are labeled with $*$. 
Proposition 1 (No Facility Equilibrium): Define

$$
\bar{\gamma}:=\frac{i^{R O}+\alpha-i^{D F}}{S^{t}}, \quad \overline{\bar{\gamma}}:=\frac{i^{L F}-i^{R O}}{D_{H}-D^{t}},
$$

and suppose that $\gamma \leq \bar{\gamma}<\overline{\bar{\gamma}}$. Then, the interbank market equilibrium is characterized by

$$
T^{*}=S^{t}, \quad i^{I B M *}=i^{R O}+\alpha-\gamma S^{t} \geq i^{D F} .
$$

The commercial banks will choose

$$
\begin{array}{ll}
R O^{d *}=D^{t}-S^{t}=\mathfrak{D}, & R O^{s *}=0, \\
B_{k}^{d *}=D_{k}-\mathfrak{D}, & B_{k}^{s *}=-S_{k}, \\
D F_{k}^{d *}=0, & D F_{k}^{s *}=0, \\
L F_{k}^{d *}=0, & L F_{k}^{s *}=0 .
\end{array}
$$

Proof: see appendix.

The proposition clarifies the equilibrium in case of small participation costs $\gamma \leq \bar{\gamma}$. In this No Facility Equilibrium, the deficit banks borrow the aggregate autonomous deficit $\mathfrak{D}$ in the central bank's refinancing operation, see (17). Then, via the interbank market, the surplus banks reallocate their total liquidity surplus $S^{t}$ to the deficit banks, see (16) and (18). Accordingly, (19) and (20) state that neither the deposit nor the lending facility is used. Depending on the magnitude of the participation costs, the interbank rate lies between the rate $i^{D F}$ on the deposit facility and the marginal costs $i^{R O}+\alpha$ of the refinancing operation, see (16).

The interbank market plays a central role for this equilibrium. In this market, the surplus banks are willing to lend their total surplus $S^{t}$ as long as the marginal return $i^{I B M *}$ of lending this amount is weakly higher than the marginal return $i^{D F}$ of the deposit facility. Their liquidity supply is perfectly inelastic for $i^{I B M *} \geq i^{D F}$. The incentives of 
the deficit banks are a bit more complex. A deficit bank's expected autonomous deficit is equal to $E[D]=D^{t}$. Therefore, obtaining the aggregate deficit $\mathfrak{D}$ in the refinancing operation and not using the facilities implies that the bank expects to borrow $D^{t}-\mathfrak{D}$ in the interbank market. We know from (7) that this expected borrowing volume coincides with the aggregate surplus of the surplus banks, $D^{t}-\mathfrak{D}=S^{t}$. This borrowing volume will be optimal for the deficit bank if two conditions are met: First, the expected marginal costs of interbank borrowing, which consist of the interbank rate $i^{I B M *}$ and the expected marginal participation costs $\gamma E\left[B_{k}^{d *}\right]$, must be equal to the marginal costs $i^{R O}+\alpha$ of the refinancing operation. It is the equilibrium interbank rate $i^{I B M *}$ which ensures that this first optimality condition is fulfilled, see (16). If, for example, $i^{I B M *}$ were smaller, the marginal costs of the refinancing operation would exceed the expected marginal costs of interbank borrowing. Consequently, the deficit bank would prefer to cover a larger part of its deficit in the interbank market. However, this is impossible since the supply in this market is limited to $S^{t}$. The second condition refers to the situation in which the autonomous deficit turns out to be large so that the deficit bank has to cope with relatively large marginal participation costs in the interbank market. In this situation, the bank may not have an incentive to satisfy parts of its remaining liquidity needs $D_{H}-\mathfrak{D}$ in the lending facility. That is, the marginal costs of interbank borrowing may not exceed those of the lending facility, $i^{I B M *}+\gamma\left(D_{H}-\mathfrak{D}\right) \leq i^{L F}+\alpha$. In conjunction with $(7)$ and (16), we thus obtain $\gamma \leq \overline{\bar{\gamma}}$. This condition is met in this No Facility Equilibrium.

An increase in $\gamma$ implies for the deficit banks that their expected marginal costs of borrowing in the interbank market become higher than those of borrowing in the refinancing operation. Consequently, their demand for liquidity in the interbank market decreases. For the surplus banks an increase in $\gamma$ does not alter the marginal revenues from interbank lending. Therefore, their liquidity supply is still perfectly inelastic. As a result of the decreased demand and the inelastic supply, the equilibrium interbank rate $i^{I B M *}$ decreases until the deficit banks' expected marginal costs of borrowing in the interbank 
market equal again their marginal costs of borrowing in the refinancing operation. The transaction volume $T^{*}$ does not change, the complete surplus of all surplus banks is still reallocated to the deficit banks. Thus, there is only a price effect and no quantity effect in the interbank market.

The further the participation costs $\gamma$ increase in the No Facility Equilibrium, the lower the interbank rate will be. However, the interbank rate must remain (weakly) higher than the marginal return of the deposit facility, $i^{I B M *} \geq i^{D F}$, because otherwise, the surplus banks would have no reason to supply liquidity in the interbank market. They would use the deposit facility instead. In conjunction with (16) this yields $\gamma \leq \bar{\gamma}$, which is met in the No Facility Equilibrium.

Obviously, a complete reallocation of liquidity from the surplus banks to the deficit banks will be out of reach whenever the participation costs $\gamma$ exceed the threshold $\bar{\gamma}$. In this case, the interbank rate ought to fall below the rate on the deposit facility to compensate the deficit banks for the higher participation costs. However, this would induce the surplus banks to deposit their liquidity in the deposit facility. This leads us to:

Proposition 2 (Deposit Facility Equilibrium): Suppose that $\gamma \in(\bar{\gamma}, \overline{\bar{\gamma}}]$. Then, the interbank market equilibrium is characterized by

$$
T^{*}=\frac{i^{R O}+\alpha-i^{D F}}{\gamma}, \quad \quad i^{I B M *}=i^{D F} .
$$

The commercial banks will choose

$$
\begin{array}{ll}
R O^{d *}=D^{t}-\frac{i^{R O}+\alpha-i^{D F}}{\gamma}>\mathfrak{D}, & R O^{s *}=0, \\
B_{k}^{d *}=D_{k}-R O^{d *}, & B_{k}^{s *}=-T^{*}, \\
D F_{k}^{d *}=0, & D F_{k}^{s *}=S_{k}-T^{*}, \\
L F_{k}^{d *}=0, & L F_{k}^{s *}=0 .
\end{array}
$$

Proof: see appendix. 
The second equilibrium type emerges in case of intermediate interbank market participation costs, $\gamma \in(\bar{\gamma}, \overline{\bar{\gamma}}]$. Here, the deficit banks borrow beyond the aggregate autonomous deficit $\mathfrak{D}$ of the banking sector in the central bank's refinancing operation, see (22). They close their remaining deficit $D_{k}-R O^{d *}$, which is obviously smaller than in the No Facility Equilibrium, in the interbank market, the lending facility remains unused, see (23) and (25). However, as the deficit banks obtain more than $\mathfrak{D}$ in the refinancing operation, the surplus banks do not place their complete surplus in the interbank market, they allocate some liquidity to the deposit facility in this Deposit Facility Equilibrium, see (24). The interbank rate coincides with the rate $i^{D F}$ on the deposit facility, see (21).

After the refinancing operation has taken place, there is excess liquidity in the banking sector. Therefore, the interbank rate will decrease until the surplus banks are indifferent between interbank lending and the deposit facility, $i^{I B M *}=i^{D F}$. At this interbank rate, their liquidity supply in the interbank market is perfectly elastic up to the amount $S^{t}$. With respect to the deficit banks' demand in this market, there are again two relevant conditions. The first condition relates to their behavior in the central bank's refinancing operation. If a deficit bank obtains $R O^{d *}$ from the central bank, it will expect to borrow $R O^{d *}-D^{t}$ in the interbank market. Accordingly, it will expand borrowing in the refinancing operation until its expected marginal costs in the interbank market are equal to the marginal costs of the refinancing operation, $i^{D F}+\gamma\left(R O^{d *}-D^{t}\right)=i^{R O}+\alpha$, see $(22)$. The second condition relates to the deficit banks' behavior in case of a high autonomous deficit $D_{H}$. To ensure that even in this case, in which participation costs are relatively high, a deficit bank prefers interbank borrowing over the lending facility, the marginal costs of borrowing the amount $D_{H}-R O^{d *}$ in this market may not exceed the lending facilities' marginal costs, $i^{D F}+\gamma\left(D_{H}-R O^{d *}\right) \leq i^{L F}+\alpha$. In conjunction with (22), this requirement results in $\gamma \leq \overline{\bar{\gamma}}$, which is met in the Deposit Facility Equilibrium.

An increase in $\gamma$ implies that the deficit banks' expected marginal costs of borrowing in the interbank market become higher than those of borrowing in the refinancing operation. 
Their demand in the interbank market decreases. For the surplus banks marginal revenues $i^{I B M}$ of their interbank market transactions remain balanced with the marginal revenues $i^{D F}$ of the deposit facility so that their liquidity supply in the interbank market remains perfectly elastic. Consequently, an increase in $\gamma$ leaves the interbank rate unchanged but lowers the transaction volume in the interbank market. Consequently, in this equilibrium, a change in $\gamma$ involves only a quantity effect but no price effect.

If $\gamma$ increases beyond $\overline{\bar{\gamma}}$, participation in the interbank market will be that costly that those deficit banks facing a high deficit $D_{H}$ prefer to satisfy parts of their liquidity needs in the lending facility. This brings us to the third and last type of equilibrium:

Proposition 3 (Both Facilities Equilibrium): Suppose that $\gamma>\overline{\bar{\gamma}}>\bar{\gamma}$. Then, the interbank market equilibrium is characterized by

$$
T^{*}=\frac{i^{R O}+\alpha-i^{D F}}{\gamma}, \quad \quad i^{I B M *}=i^{D F} .
$$

The commercial banks will choose

$$
\begin{array}{ll}
R O^{d *}=D_{L}-\frac{i^{R O}+\alpha-i^{D F}}{\gamma}+\frac{i^{L F}-i^{R O}}{\gamma}>\mathfrak{D}, & R O^{s *}=0, \\
B_{L}^{d *}=T^{*}-\frac{i^{L F}-i^{R O}}{\gamma}, & B_{L}^{s *}=-T^{*}, \\
B_{H}^{d *}=T^{*}+\frac{i^{L F}-i^{R O}}{\gamma}, & B_{H}^{s *}=-T^{*}, \\
D F_{k}^{d *}=0, & D F_{k}^{s *}=S_{k}-T^{*}, \\
L F_{L}^{d *}=0, & L F_{L}^{s *}=0, \\
L F_{H}^{d *}=D_{H}-D_{L}-2 \frac{i^{L F}-i^{R O}}{\gamma}, & L F_{H}^{s *}=0 .
\end{array}
$$

Proof: see appendix.

In case of the third equilibrium type with $\gamma>\overline{\bar{\gamma}}$, the deficit banks still borrow more than the aggregate deficit $\mathfrak{D}$ in the refinancing operation, see (27). Consequently, (30) states that the surplus banks still allocate some liquidity to the deposit facility. The 
interbank rate is still equal to the rate on the deposit facility, see (26). However, a deficit bank having a large deficit $D_{H}$ finds it too costly to rely solely on the interbank market so that the lending facility is also used in this Both Facilities Equilibrium, see (32).

In the Both Facilities Equilibrium, the properties of the interbank market are similar to those in the Deposit Facility Equilibrium. As there is again excess liquidity in the banking sector, the interbank rate is again equal to $i^{D F}$ and the supply of the surplus banks is again perfectly elastic. With respect to the deficit banks, the situation is again a bit more complex. According to (27), the deficit banks borrow an amount $R O^{d *}$ in the refinancing operation, which satisfies

$$
\frac{1}{2}\left(i^{I B M *}+\gamma\left(D_{L}-R O^{d *}\right)\right)+\frac{1}{2}\left(i^{L F}+\alpha\right)=i^{R O}+\alpha .
$$

This optimal amount $R O^{d *}$ balances the marginal costs of the refinancing operation (right hand side of (33)) with the expected marginal costs of borrowing in the interbank market and in the lending facility (left hand side of (33)). To understand these expected marginal costs, consider a deficit bank that has received $R O^{d *}$ in the refinancing operation. If it turns out that the bank has a low deficit $D_{L}$, it will use the interbank market to cover its remaining deficit $D_{L}-R O^{d *}$ so that the marginal borrowing costs are $i^{I B M *}+\gamma\left(D_{L}-\right.$ $\left.R O^{d *}\right)$, see the first term on the left hand side of (33). However, if a deficit bank has to cope with a high deficit $D_{H}$, it will also use the lending facility. In this case, marginal costs are $i^{L F}+\alpha$, see the second term on the left hand side of (33).

Obviously, also in the Both Facilities Equilibrium, an increase in $\gamma$ makes interbank borrowing less attractive, so that the demand of the deficit banks in this market shrinks. In conjunction with the perfectly elastic supply of the surplus banks, this lowers the transaction volume in the interbank market without changing the interbank rate. Therefore, like in the Deposit Facility Equilibrium, an increase in $\gamma$ has only a quantity effect in the interbank market. 
It is interesting to note what happens when the participation costs in the interbank market tend to infinity, $\gamma \rightarrow \infty$. Then, the transaction volume in the interbank market approaches zero and the deficit banks use the refinancing operation to cover the certain part of their autonomous liquidity deficit, $T^{*}=0$ and $R O^{d *}=D_{L}$, see (26) and (27). ${ }^{20}$ In case the autonomous deficit is large, the banks will use the lending facility to satisfy their remaining liquidity needs $D_{H}-D_{L}$, see (32). From this, we can draw two general conclusions: First, independently of $\gamma$, a low-deficit bank will never borrow in the lending facility and a high deficit bank will never borrow more than $D_{H}-D_{L}$ in this facility. The reason is that no bank will borrow in the lending facility to cover the certain part of its autonomous liquidity deficit, since the per unit costs of covering this part of the deficit right from the beginning in the refinancing operation are lower, $i^{R O}+\alpha<i^{L F}+\alpha$. Second, independently of $\gamma$, no bank will borrow more than $D_{L}$ in the refinancing operation. Here, the reason is that expected per unit costs of covering the uncertain part of the autonomous deficit, which is equal to $D_{H}-D_{L}$, are lower when using the lending facility instead of borrowing in the refinancing operation:

$$
\left(i^{R O}+\alpha\right)-\frac{1}{2} i^{D F}>\frac{1}{2}\left(i^{L F}+\alpha\right)
$$

The left hand side of (34) presents the expected net per unit costs of borrowing the uncertain amount $D_{H}-D_{L}$ in the refinancing operation. The first term reflects interest and collateral costs, the second term reflects interest revenues in case this liquidity is not needed because $D_{L}$ is realized. The right hand side of (34) shows the expected costs of covering the uncertain liquidity needs by borrowing in the lending facility if necessary. Rearranging (34) yields $i^{R O}+0.5 \alpha>0.5\left(i^{L F}+i^{D F}\right)$. This inequality holds since the rates on the facilities form a symmetric corridor around the rate on the refinancing operation $\left(i^{R O}=0.5\left(i^{L F}+i^{D F}\right)\right)$. Intuitively, banks do not cover their uncertain liquidity needs

\footnotetext{
${ }^{20}$ The amount $D_{L}$ reflects the bank's certain liquidity needs in the sense that the bank will need at least this amount of liquidity in any state of the world. Accordingly, the difference $D_{H}-D_{L}$ reflects the bank's uncertain part of its liquidity needs.
} 

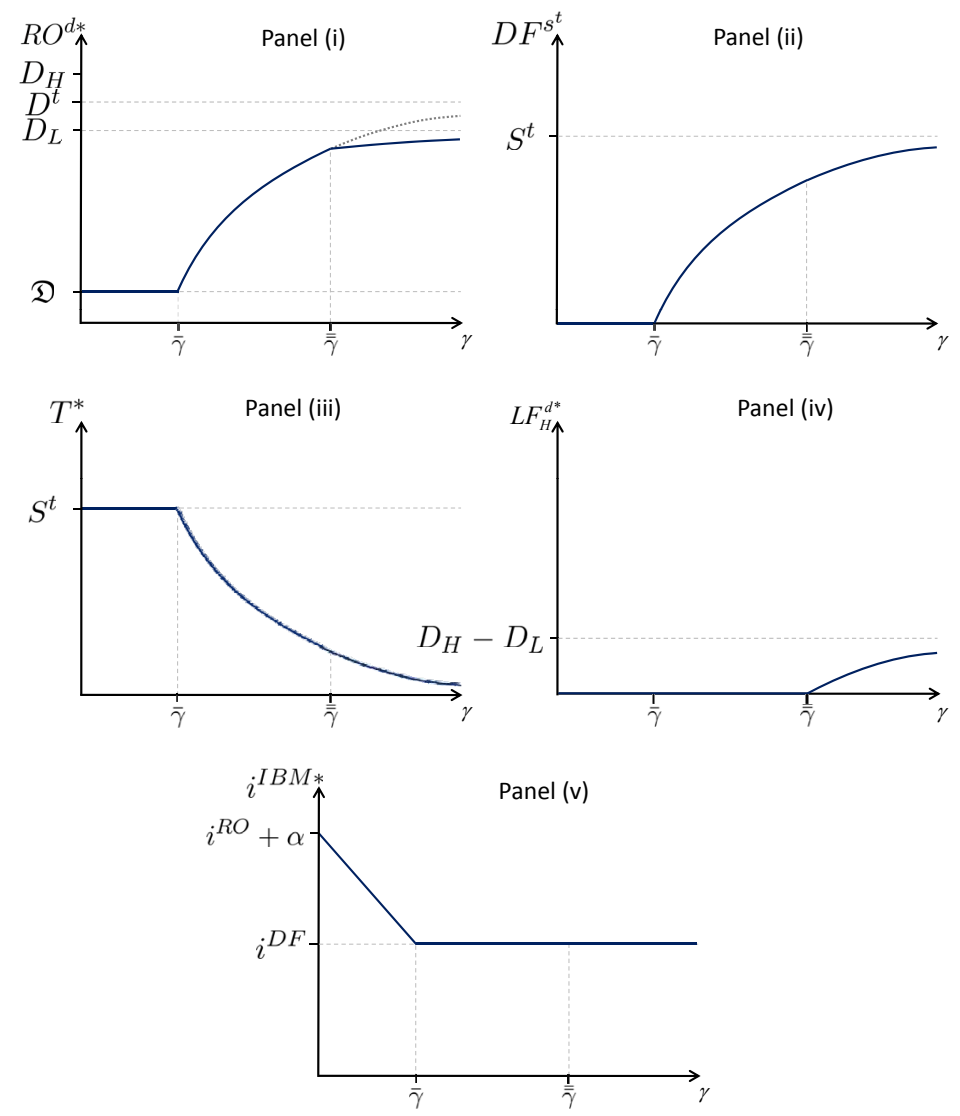

Figure 3: Relevant Model Variables against Participation Costs

by borrowing in the refinancing operation because then, the marginal collateral costs will accrue for certain, while they will accrue only with probability 0.5 if the bank relies on the lending facility whenever necessary.

In this section, we have seen that depending on the magnitude of the participation $\operatorname{costs} \gamma$ in the interbank market, three different types of equilibrium may arise. Figure 3 provides a graphical summary of the three equilibrium types by illustrating the relationship between $\gamma$ and the relevant model variables.

\section{Discussion}

\subsection{Model Results and Stylized Facts}

In section 4, we have identified the following stylized facts for the euro area: Since September 2008, there has been (1) a strong increase in the banking sector's demand for reserves 
in the Eurosystem's open market operations, which has exceeded by far the banking sector's needs for reserves arising from autonomous factors and the reserve requirement, (2) a significant decrease in transactions in the interbank market for reserves, (3) a strong recourse to the deposit facility, and (4) a systematic fall of the EONIA below the MROrate, close to the rate on the deposit facility. Moreover, directly after the fall of Lehman Brothers, there has been (5) a significant but relatively small recourse to the marginal lending facility.

In our model, the "Deposit Facility Equilibrium" and, when considering the period directly after the collapse of Lehman Brothers, the "Both Facilities Equilibrium" fit exactly to these developments. Based on our theoretical analysis we therefore argue that the stylized facts can be explained by a strong increase in the level of participation costs in the overnight interbank market, as measured by $\gamma$. During the financial crisis, these costs increased substantially because commercial banks suffered from high bank asset losses. Besides, in an environment of high uncertainty, there was significant asymmetric information in how far individual banks were affected by the crisis. Since lenders in the overnight interbank market are unwilling to expose themselves to any counterparty credit risk, the increased uncertainty made things more difficult for banks in need of liquidity. Credit lines were cut so that they had to intensify their search for suitable counterparties. Moreover, they had to put more effort in successfully signaling their creditworthiness. There may also have been fears that demanding large amounts of liquidity might harm their reputation. In the context of our model, all these developments are associated with an increase in $\gamma$.

As borrowing in the interbank market became increasingly costly, deficit banks preferred to cover a larger part of their liquidity needs in the Eurosystem's open market operations instead of relying on the interbank market. The demand for reserves in the open market operations rose beyond the banking sector's needs for reserves arising from autonomous factors and the reserve requirement. Since the Eurosystem fully satisfied 
this increased demand, the demand for liquidity in the interbank market decreased. This brought down the interbank rate close to its lower bound, the rate on the deposit facility. Banks having excess liquidity were no longer able to place their full liquidity surplus in the interbank market at acceptable conditions. Therefore, they used the deposit facility. Transactions in the interbank market declined.

The degree of uncertainty was particularly high directly after the collapse of Lehman Brothers in September 2008, after the Greek sovereign crisis became apparent in December 2009 and when the sovereign debt crisis in the euro area intensified in the summer 2011. Accordingly, also the costs of participating in the interbank market were soaring during these periods. This explains why borrowing in the central bank's open market operation as well as the recourse to the deposit facility increased further during these periods while the transaction volume in the interbank market fell. Directly after the collapse of Lehman Brothers, the participation costs in the interbank market were even that high that deficit banks took recourse to the marginal lending facility as the Both Facilities Equilibrium of our model would predict.

Two aspects are particularly noteworthy. First, the high interbank market participation costs implied that the Eurosystem assumed an intermediary function. Surplus banks placed their excess liquidity at the Eurosystem while deficit banks borrowed liquidity directly from the Eurosystem. This intermediary function was reinforced by measures the Eurosystem adopted during the crisis. It narrowed the symmetric corridor that the rates on the facilities form around the MRO-rate and it reduced the collateral requirements in credit operations. Both measures raised the attractiveness of transactions with the Eurosystem relative to interbank market transactions. In our model, the former measure is reflected by an increase in $i^{D F}$ and a decrease in $i^{C F}$. The latter measure is reflected by a decrease in $\alpha$. The Propositions 2 and 3 show that both measures imply a decrease in the interbank market transaction volume $T^{*}$. 
The second aspect refers to the massive recourse to the deposit facility. It has been argued that this facility has been used for precautionary reasons (see, for example, Trichet, 2009). However, theoretical models dealing with liquidity hoarding for precautionary reasons do not consider specific institutional features of the euro area as, for example, the two facilities offered by the central bank (see, for example, Allen, Carletti, and Gale, 2009; Caballero and Krishnamurthy, 2008; Ashcraft, McAndrews, and Skeie, 2011), which should mitigate the banks' incentive to hoard liquidity, particularly as borrowing at the Eurosystems' lending facility does not involve stigma costs (Cassola, Holthausen, and Würtz, 2009). In our model, which accounts for a lending facility as offered by the Eurosystem, it is not rational for commercial banks to hoard liquidity in the deposit facility for precautionary reasons. If they did so, they would cover uncertain liquidity needs by borrowing in the Eurosystem's tender procedures. However, borrowing in the tender procedures and hoarding the liquidity in the deposit facility as a precaution is more expensive than using the credit facility if necessary. Consequently, we offer a further explanation for the strong use of the deposit facility. Our model suggests that it has been used by surplus banks, which were unable to place their excess liquidity in the interbank market at reasonable rates since the high participation costs induced deficit banks to borrow from the central bank rather than in the interbank market. This view is supported by evidence showing that most of the banks using the deposit facility have not participated in the preceding main refinancing operation conducted by the Eurosystem (see, for example, European Central Bank, 2009).

\subsection{Policy Implications}

As pointed out in the introduction, the disadvantage of a centrally organized interbank market, in which the central bank assumes an intermediary function, is a less efficient allocation of liquidity. An obvious way to reverse the intermediary function of the ECB would lie in a reduction of interbank market participation costs. However, these high costs are the result of high uncertainty about how strongly individual banks are affected 
by asset losses, and therefore, about their creditworthiness. These problems cannot be solved by the central bank, i.e. central bank measures cannot reduce these participation costs.

The Eurosystem could reactivate interbank market activities by making borrowing from and placing liquidity at the central bank less attractive. This could be achieved, for example, by tightening the criteria for eligible collateral or by expanding the corridor that the rates on the facilities form around the MRO-rate. However, as long as participation in the interbank market is costly, this would increase the banks' liquidity costs and/or might even provoke liquidity problems in the banking sector. Consequently, the Eurosystem faces a trade-off. On the one hand, it aims at reactivating interbank market activities. In a situation of high participation costs, measures to reactivate the interbank market lead to increasing liquidity costs for the banking sector. On the other hand, it aims at supporting the general economic policy of the EU (as long as its primary objective to maintain price stability is not prejudiced) and to reestablish the stability of the banking sector in a financial crisis (González-Páramo, 2009). These objectives may require a policy leading to low liquidity costs for the banks.

During the financial crisis, the Eurosystem adopted several non-standard measures with the aim to avoid substantial financial instabilities. We described these measures briefly in section 2. Consistent with the trade-off between reactivating the interbank market and keeping liquidity costs low for the banking sector, the ECB decided to phase out its non-standard-measures "in line with the ongoing normalisation of conditions in financial intermediation relevant to the transmission mechanism. Their withdrawal will be gradual..." (European Central Bank, 2011a, p. 68.). In the context of our model, this means that if participation costs in the interbank market decrease, as uncertainty problems become less severe, the intermediation function of the ECB will become less important, and the ECB will gradually withdraw non-standard measures, making transactions between 
the banking sector and the ECB less attractive and thereby further reactivating interbank market activities.

One factor which strained financial stability during the crisis was the exclusion of banks in specific euro area countries from interbank markets. These so called addicted banks were fully dependent on the Eurosystem's liquidity provision (Deutsche Bundesbank, 2010). While an explicit investigation of this issue clearly is outside the scope of our model, it still can provide some tentative insight into this issue. If the participation costs $\gamma$ in the interbank market tended to infinity, $\gamma \rightarrow \infty$, all deficit banks in our model could been seen as so called addicted banks, which have no access to the interbank market. In this extreme case, the Both Facilities Equilibrium would emerge. All deficit banks would cover their deficit solely by borrowing from the central bank $\left(R O^{d *}=D_{L}\right.$ and $\left.L F_{H}^{d *}=D_{H}-D_{L}\right)$. All surplus banks would place their complete excess liquidity in the deposit facility $\left(D F_{k}^{s *}=S_{k}\right)$ and there would be no transactions in the interbank market $\left(T^{*}=0\right)$. These results may serve as an interesting starting point for future research.

The financial crisis affected the banking sector in all euro area countries, although to a varying extent. This heterogeneity has the potential to cause significant differences in the transmission of the Eurosystem's single monetary policy (Smaghi, 2011). The Eurosystem reacted to this problem by implementing the described intended temporary non-standard measures. These measures "have addressed ... the country specific impediments to the monetary policy transmission" (Smaghi, 2011). However, an important issue for future research is to discuss the role of the Eurosystem and to analyze the consequences for monetary policy implementation if the cross-country differences in banking sector soundness and, therefore, in the banks' access to external funding and thus in the cost of financing for the private sector persists for a longer period of time. Obviously, this heterogeneity is a problem for monetary policy transmission and leads to new challenges for monetary policy implementation. 


\section{Summary}

Starting with the collapse of Lehman Brothers in September 2008, there was a strong increase in the euro area banking sector's demand for reserves in the Eurosystem's open market operations, a massive decrease in interbank market transactions together with a systematic fall of the EONIA below the MRO-rate, and a strong recourse to the deposit facility.

This paper theoretically explains these stylized facts and draws some policy implications. It is shown that the stylized facts can be explained by a strong increase in participation costs on the interbank market in combination with a nearly unlimited liquidity supply of the central bank. The increased participation costs imply that banks having a liquidity deficit cover their deficit by borrowing from the central bank rather than in the interbank market. This induces banks with a liquidity surplus to place their excess liquidity in the central bank's deposit facility. Thus, the central bank assumes an intermediary function between banks. The result is an aggregate liquidity surplus in the banking sector which leads to a systematic fall of the EONIA below the policy rate. Concerning the implications for the Eurosystem's liquidity management we argue that as long as the interbank market does not function properly, measures to reactivate this market conflict with aims from the monetary policy perspective and the financial stability perspective. 


\section{Appendix}

We prove the propositions in two steps. First, we solve the two-stage optimization problem of an individual bank of type $j=d, s$. Then, we determine the equilibrium of the model.

\section{A. Optimization Problem of a Bank}

Henceforth, we make use of the variable $A^{j}$, which reflects the autonomous liquidity needs of a type $j$ bank. $A^{j}>0$ indicates an autonomous deficit, $A^{j}<0$ indicates an autonomous surplus. Accordingly, we can define $A_{L}^{d}:=D_{L}, A_{H}^{d}:=D_{H}, A_{L}^{s}:=-S_{L}$ and $A_{H}^{s}:=-S_{H}$. A bank faces a two-stage optimization problem that can be solved by backward induction.

\section{A.1 Second Stage Optimization Problem}

Consider a bank of type $j$ with $j=d, s$. Inserting (2), (3), (4) and the definitions of $A_{k}^{j}$ with $k=L, H$ in (8) and (9) as well as (11) and (12) respectively and rearranging terms reveals that the bank's second stage optimization problem reads:

$$
\begin{gathered}
i^{I B M} B_{k}^{j}+\frac{1}{2} \gamma \max \left\{0, B_{k}^{j}\right\}^{2}+\left(i^{L F}+\alpha\right) L F_{k}^{j}-i^{D F} D F_{k}^{j}=: f(\cdot) \rightarrow \min \\
\text { s.t. } L F_{k}^{j}-D F_{k}^{j}=A_{k}^{j}-R O^{j}-B_{k}^{j} .
\end{gathered}
$$

From (35), (36) and $i^{D F}<i^{L F}+\alpha$, we can conclude:

Result LF/DF: Suppose the interbank market position $B_{k}^{j}$ is given. Then, we obtain:

$$
\begin{array}{llrl}
L F_{k}^{j, o p t}=A_{k}^{j}-R O^{j}-B_{k}^{j}, & D F_{k}^{j, o p t}=0 & \text { if } \quad B_{k}^{j}<A_{k}^{j}-R O^{j}, \\
L F_{k}^{j, o p t}=0 & D F_{k}^{j, \text { opt }}=B_{k}^{j}+R O^{j}-A_{k}^{j} & \text { if } \quad B_{k}^{j} \geq A_{k}^{j}-R O^{j} .
\end{array}
$$

Insertion of Result LF/DF in (35) yields:

$$
f\left(B_{k}^{j}\right)=i^{I B M} B_{k}^{j}+\frac{1}{2} \gamma \max \left\{0, B_{k}^{j}\right\}^{2}+\iota\left(A_{k}^{j}-R O^{j}-B_{k}^{j}\right)
$$


with $\iota=i^{L F}+\alpha$ for $B_{k}^{j}<A_{k}^{j}-R O^{j}$ and $\iota=i^{D F}$ for $B_{k}^{j} \geq A_{k}^{j}-R O^{j}$. From (37), we obtain:

$$
f^{\prime}\left(B_{k}^{j}\right)=i^{I B M}+\gamma \max \left\{0, B_{k}^{j}\right\}-\iota
$$

Note that $f^{\prime}\left(B_{k}^{j}\right)$ is (weakly) increasing in $B_{k}^{j}$, so that we obtain:

- If $i^{I B M}<i^{D F}$, then $f^{\prime}\left(B_{k}^{j}\right)<0$ for all $B_{k}^{j} \leq 0$. This implies $B_{k}^{j, o p t}>0$.

- If $i^{I B M}>i^{L F}+\alpha$, then $f^{\prime}\left(B_{k}^{j}\right)>0$ for all $B_{k}^{j} \geq 0$. This implies $B_{k}^{j, o p t}<0$.

As both cases are in conflict with the interbank market clearing condition (14), we can restrict attention to $i^{I B M} \in\left[i^{D F}, i^{L F}+\alpha\right]$. Given this restriction, (38) implies

Result B: For a given interbank rate $i^{I B M}$, we have:

- If $A_{k}^{j}-R O^{j} \leq 0$, then:

$$
\begin{array}{ll}
B_{k}^{j, \text { opt }} \in\left[A_{k}^{j}-R O^{j}, 0\right] & \text { if } i^{I B M}=i^{D F}, \\
B_{k}^{j, \text { opt }}=A_{k}^{j}-R O^{j} & \text { if } \quad i^{I B M} \in\left(i^{D F}, i^{L F}+\alpha\right), \\
B_{k}^{j, \text { opt }} \in\left[-\infty, A_{k}^{j}-R O^{j}\right] & \text { if } \quad i^{I B M}=i^{L F}+\alpha .
\end{array}
$$

- If $A_{k}^{j}-R O^{j}>0$, then:

$$
\begin{array}{ll}
B_{k}^{j, \text { opt }}=\min \left\{A_{k}^{j}-R O^{j}, \frac{i^{L F}+\alpha-i^{I B M}}{\gamma}\right\} & \text { if } \quad i^{I B M} \in\left[i^{D F}, i^{L F}+\alpha\right), \\
B_{k}^{j, \text { opt }} \in[-\infty, 0] & \text { if } \quad i^{I B M}=i^{L F}+\alpha .
\end{array}
$$

\section{A.2 First Stage Optimization Problem}

Consider a bank of type $j$ with $j=d, s$ and restrict attention to $i^{I B M} \in\left[i^{D F}, i^{L F}+\alpha\right]$.

We know from (10) and (13) in conjunction with (1) and (37), that the bank's first stage optimization problem reads:

$$
\left(i^{R O}+\alpha\right) R O^{j}+\frac{1}{2} f\left(B_{L}^{j, o p t}\right)+\frac{1}{2} f\left(B_{H}^{j, o p t}\right)=: g\left(R O^{j}\right) \rightarrow \min .
$$


In conjunction with (37), (38) and Result B, this brings us to:

$$
\begin{aligned}
g^{\prime}\left(R O^{j}\right)=\left(i^{R O}+\alpha\right) & -\frac{1}{2} \min \left\{i^{I B M}+\gamma \max \left\{0, A_{L}^{j}-R O^{j}\right\}, i^{L F}+\alpha\right\} \\
& -\frac{1}{2} \min \left\{i^{I B M}+\gamma \max \left\{0, A_{H}^{j}-R O^{j}\right\}, i^{L F}+\alpha\right\} .
\end{aligned}
$$

Note that $i^{I B M}>i^{R O}+\alpha$ implies $R O^{j, o p t} \rightarrow \infty$. In conjunction with Result $\mathrm{B}$, this yields $B_{k}^{j, \text { opt }} \rightarrow-\infty$, which conflicts with (14). Therefore, we can further narrow the set of interbank rates to $i^{I B M} \in\left[i^{D F}, i^{R O}+\alpha\right]$.

\section{Surplus Bank}

For a surplus bank, inserting $j=s, A_{L}^{s}=-S_{L}$ and $A_{H}^{s}=-S_{H}$ in (39) yields $g^{\prime}\left(R O^{s}\right)=$ $\left(i^{R O}+\alpha\right)-i^{I B M}$ for all $R O^{s} \geq 0$. This implies

Result $\mathbf{R O}^{S}$ : For a given interbank rate $i^{I B M}$, we have

$$
\begin{array}{ll}
R O^{s, o p t}=0 & \text { if } \quad i^{I B M} \in\left[i^{D F}, i^{L F}+\alpha\right), \\
R O^{s, o p t} \in[0, \infty) & \text { if } \quad i^{I B M}=i^{L F}+\alpha .
\end{array}
$$

Using $E\left[B^{s, o p t}\right]:=0.5 B_{L}^{s, o p t}+0.5 B_{H}^{s, o p t}$, insertion of Result $\mathrm{RO}^{S}$ in Result B yields:

Result $\mathbf{B}^{S}$ : For a given interbank rate $i^{I B M}$, we have

$$
\begin{array}{ll}
E\left[B^{s, o p t}\right] \in\left[-S^{t}, 0\right] & \text { if } i^{I B M}=i^{D F}, \\
E\left[B^{s, o p t}\right]=-S^{t} & \text { if } i^{I B M} \in\left(i^{D F}, i^{L F}+\alpha\right), \\
E\left[B^{s, o p t}\right] \in\left(-\infty,-S^{t}-R O^{s, o p t}\right] & \text { if } i^{I B M}=i^{L F}+\alpha .
\end{array}
$$

\section{Deficit Bank}

For a deficit bank, inserting $j=d, A_{L}^{d}=D_{L}$ and $A_{H}^{d}=D_{H}$ in (39) yields:

$$
\begin{aligned}
g^{\prime}\left(R O^{d}\right)=\left(i^{R O}+\alpha\right) & -\frac{1}{2} \min \left\{i^{I B M}+\gamma \max \left\{0, D_{L}-R O^{d}\right\}, i^{L F}+\alpha\right\} \\
& -\frac{1}{2} \min \left\{i^{I B M}+\gamma \max \left\{0, D_{H}-R O^{d}\right\}, i^{L F}+\alpha\right\} .
\end{aligned}
$$


According to (40), we have $g^{\prime}\left(R O^{d}\right)<0$ for all $R O^{d} \leq D_{L}-\frac{i^{L F}+\alpha-i^{I B M}}{\gamma}$. Therefore, we can restrict attention to $R O^{d}>D_{L}-\frac{i^{L F}+\alpha-i^{I B M}}{\gamma}$, so that we can rewrite (40) to

$$
\begin{aligned}
g^{\prime}\left(R O^{d}\right)=\left(i^{R O}+\alpha\right) & -\frac{1}{2}\left(i^{I B M}+\gamma \max \left\{0, D_{L}-R O^{d}\right\}\right) \\
& -\frac{1}{2} \min \left\{i^{I B M}+\gamma \max \left\{0, D_{H}-R O^{d}\right\}, i^{L F}+\alpha\right\} .
\end{aligned}
$$

Now, note that $g^{\prime}\left(R O^{d}\right)$ is (weakly) increasing in $R O^{d}$ and that $g^{\prime}\left(D_{L}\right) \geq 0$ only if $i^{I B M} \leq$ $\widehat{i}^{I B M}$, where $\widehat{i}^{I B M}$ is implicitly defined by

$$
i^{R O}+\alpha=\frac{1}{2} \widehat{i}^{I B M}+\frac{1}{2} \min \left\{\hat{i}^{I B M}+\gamma\left(D_{H}-D_{L}\right), i^{L F}+\alpha\right\}
$$

which implies:

$$
\widehat{i}^{I B M}:= \begin{cases}i^{R O}+\alpha-\gamma\left(D_{H}-D^{t}\right)>i^{D F} & \text { if } \quad \gamma \leq \frac{i^{L F}-i^{R O}}{D_{H}-D^{t}}=: \overline{\bar{\gamma}} \\ i^{R O}+\alpha-\left(i^{L F}-i^{R O}\right)>i^{D F} & \text { if } \quad \gamma>\frac{i^{L F}-i^{R O}}{D_{H}-D^{t}}=: \overline{\bar{\gamma}}\end{cases}
$$

Accordingly, (41) leads to

Result $\mathbf{R O}^{D}$ : For a given interbank rate $i^{I B M}$, we have:

$$
\begin{aligned}
& R O^{d, o p t}=D^{t}-\frac{i^{R O}+\alpha-i^{I B M}}{\gamma} \leq D_{L} \quad \text { if } \quad i^{I B M} \in\left[i^{D F}, \widehat{i}^{I B M}\right], \gamma \leq \frac{i^{L F}-i^{R O}}{D_{H}-D^{t}} \\
& R O^{d, o p t}=D_{L}-\frac{i^{R O}+\alpha-i^{I B M}}{\gamma}+\frac{i^{L F}-i^{R O}}{\gamma} \leq D_{L} \quad \text { if } \quad i^{I B M} \in\left[i^{D F}, \hat{i}^{I B M}\right], \gamma>\frac{i^{L F}-i^{R O}}{D_{H}-D^{t}}, \\
& R O^{d, o p t}=D_{H}-2 \frac{i^{R O}+\alpha-i^{I B M}}{\gamma}>D_{L} \quad \text { if } i^{I B M} \in\left(\widehat{i}^{I B M}, i^{R O}+\alpha\right), \\
& R O^{d, o p t} \in\left[D_{H}, \infty\right) \quad \text { if } i^{I B M}=i^{R O}+\alpha .
\end{aligned}
$$

Using $E\left[B^{d, o p t}\right]:=0.5 B_{L}^{d, o p t}+0.5 B_{H}^{d, o p t}$, insertion of Result $\mathrm{RO}^{D}$ in Result B yields:

Result $\mathbf{B}^{D}$ : For a given interbank rate $i^{I B M}$, we have:

$$
\begin{array}{ll}
E\left[B^{d, o p t}\right]=\frac{i^{R O}+\alpha-i^{I B M}}{\gamma} & \text { if } i^{I B M} \in\left[i^{D F}, \widehat{i}^{I B M}\right], \\
E\left[B^{d, o p t}\right]=2 \frac{i^{R O}+\alpha-i^{I B M}}{\gamma}-\left(D_{H}-D^{t}\right) & \text { if } i^{I B M} \in\left(\hat{i}^{I B M}, i^{R O}+\alpha\right), \\
E\left[B^{d, o p t}\right]=\left(-\infty, D^{t}-R O^{d, o p t}\right] & \text { if } i^{I B M}=i^{R O}+\alpha .
\end{array}
$$




\section{B. Equilibrium}

We will now use the interbank market clearing condition (14) to derive the equilibrium of the model. This condition requires:

$$
E\left[B^{d, o p t}\right]+E\left[B^{s, o p t}\right]=0 .
$$

Insertion of $E\left[B^{d, o p t}\right]$ and $E\left[B^{s, o p t}\right]$ as given in Result $\mathrm{BD}$ and $\mathrm{B}^{S}$ and rearranging terms yields in conjunction with $\bar{\gamma} \leq \overline{\bar{\gamma}}$ and thus $D_{H}-D^{t}<S^{t}$ :

Result EQ: In equilibrium, we have:

$$
\begin{array}{ll}
i^{I B M *}=i^{D F} & \text { if } \gamma \geq \bar{\gamma} \\
i^{I B M *}=i^{R O}+\alpha-\gamma S^{t} & \text { if } \quad \gamma>\bar{\gamma} .
\end{array}
$$

The remaining entries in the propositions, i.e. the equilibrium borrowing $R O^{j *}$ in the refinancing operation, the equilibrium position $B_{k}^{j *}$ in the interbank market, the equilibrium amount $L F_{k}^{j *}$ borrowed in the lending facility, and the equilibrium amount $D F_{k}^{j *}$ placed in the deposit facility, can then easily be found by insertion of $i^{I B M *}$ in $\operatorname{Result} \mathrm{RO}^{S}, \mathrm{RO}^{D}$, $\mathrm{B}^{S}, \mathrm{~B}^{J}$ and $L F / D F$.

\section{Bibliography}

Acharya, V. V., and O. Merrouche (2009): "Precautionary Hoarding of Liquidity and Interbank Markets: Evidence from the Sub-Prime Crisis," NYU Working Paper (New York University, Stern School of Business Research Paper Series) No. Fin-09-018.

Afonso, G., A. Kovner, and A. Schoar (2011): "Stressed, Not Frozen: The Federal Funds Market in the Financial Crisis," Journal of Finance, 66(4), 24-48.

Akerlof, G. A. (1970): "The Market for 'Lemons': Quality Uncertainty and the Market Mechanism," Quarterly Journal of Economics, 84, 488-500.

Allen, F., E. Carletti, and D. Gale (2009): "Interbank Market Liquidity and Central Bank Intervention," Journal of Monetary Economics, 56, 639-652.

Angelini, P., A. Nobili, And C. Picillo (2011): "The Interbank Market after August 2007: What Has Changed, and Why?," Journal of Money, Credit and Banking, 43, 923-958. 
Ashcraft, A., J. McAndrews, And D. Skeie (2011): "Precautionary Reserves and the Interbank Market," Journal of Money, Credit, and Banking, 43, 311-348.

Ayuso, J., And R. Repullo (2001): "Why Did the Banks Overbid? An Empirical Model of the Fixed Rate Tenders of the European Central Bank," Journal of International Money and Finance, 20, 857-870.

(2003): "A Model of the Open Market Operations of the European Central Bank," Economic Journal, 113, 883-902.

Bartolini, L., G. Bertola, and A. Prati (2001): "Banks' Reserve Management, Transaction Costs, and the Timing of Federal Reserve Intervention," Journal of Banking and Finance, 25, 1287-1317.

(2002): "Day-To-Day Monetary Policy and the Volatility of the Federal Funds Interest Rate," Journal of Money, Credit, and Banking, 34, 137-159.

Bindseil, U. (2005): "Over- and Underbidding in Central Bank Open Market Operations Conducted as Fixed Rate Tender," German Economic Review, 6, 95-130.

Bindseil, U., K. G. Nyborg, and I. A. Strebulaev (2009): "Repo Auctions and the Market for Liquidity," Journal of Money, Credit and Banking, 41, 1391-1421.

Borio, C., and P. Disyatat (2010): "Unconventional Monetary Policy: An Appraisal," Manchester School, 78, 53-89.

BräUning, F., AND F. FeCht (2012): "Relationship lending in the interbank market and the price of liquidity," Discussion Paper Deutsche Bundesbank No 22/2012.

Breitung, J., and D. Nautz (2001): "The Empirical Performance of the ECB's Repo Auctions: Evidence from Aggregated and Individual Bidding Data," Journal of International Money and Finance, 20, 839-856.

Brousseau, V., and A. Manzanares (2009): "A Look at Intraday Frictions in the Euro Area Overnight Deposit Market," European Central Bank Working Paper No. 439.

Bruche, M., And J. SuArez (2010): "Deposit Insurance and Money Market Freezes," Journal of Monetary Economics, 57, 45-61.

Brunetti, C., M. di Filippo, and J. H. Harris (2011): "Effects of Central Bank Intervention on the Interbank Market During the Subprime Crisis," Review of Financial Studies, 24, 2053-2083.

Bruno, G., M. Ordine, and A. Scalia (2005): "Banks' Participation in the Eurosystem Auctions and Money Market Integration," Discussion Paper Banca d'Italia, No. 562.

Caballero, R. J., and A. Krishnamurthy (2008): "Collective Risk Management in a Flight to Quality Episode," Journal of Finance, 63(5), 2195-2230.

Campbell, J. Y. (1987): "Money Announcements, the Demand for Bank Reserves, and the Behavior of the Federal Funds Rate Within the Statement Week," Journal of Money, Credit, and Banking, 19, 56-67. 
Cassola, N., C. Holthausen, and F. Würtz (2009): "Liquidity Management under Market Turmoil: Experience of the European Central Bank in the First Year of the 2007-2008 Financial Market Crisis," in The First Credit Market Turmoil of the 21st Century, ed. by D. D. Evanoff, P. Hartmann, and G. G. Kaufman, pp. 195-228. World Scientific Pub Co.

Cassola, N., And M. Huetr (2010): "The Euro Overnight Interbank Market and ECB's Liquidity Management Policy During Tranquil and Turbulent Times," Paper presented at the ECB Workshop on "Challenges to Monetary Policy Implementation beyond the Financial Market Turbulence", in Frankfurt/Main, Germany on 1 December 2009. Available at http://www.ecb.de/events/conferences/past/html/index.en.html.

Clouse, J. A., And J. P. Dow (1999): "Fixed Costs and the Behaviour of the Federal Funds Rate," Journal of Banking and Finance, 23, 1015-1029.

(2002): "A Computational Model of Banks' Optimal Reserve Management Policy," Journal of Economic Dynamics and Control, 26, 1787-1814.

Cocco, J. F., F. J. Gomes, and N. C. Martins (2009): "Lending relationships in the interbank market," Journal of Financial Intermediation, 18, 24-48.

Deutsche Bundesbank (2010): Financial Stability Review. November 2010.

(2011): "The Current Economic Situation in Germany," Monthly Report May 2011, pp. 5-74.

Eisenschmidt, J., A. Hirsch, And T. Linzert (2009): "Bidding Behaviour in the ECB's Main Refinancing Operations During the Financial Crisis," European Central Bank Working Paper No. 1052.

Eisenschmidt, J., And J. TAPking (2009): "Liquidity Risk Premia in Unsecured Interbank Money Markets," European Central Bank Working Paper No. 1025.

Ejerskov, S., C. M. Moss, and L. Stracca (2003): "How Does the ECB Allot Liquidity in its Weekly Main Refinancing Operations? A Look at the Empirical Evidence," Working Paper European Central Bank, No. 244.

European Central Bank (2002): "The Liquidity Management of the ECB," ECB Monthly Bulletin, May 2002, pp. 41-53.

(2007): "The Collateral Frameworks of the Federal Reserve System, the Bank of Japan and the Eurosystem," ECB Monthly Bulletin, October 200\%, pp. 85-100.

(2009): "The Implementation of Monetary Policy Since August 2007," ECB Monthly Bulletin, July 2009, pp. 75-89.

(2010): "The ECB's Response to the Financial Crisis," ECB Monthly Bulletin, October 2010, pp. 59-74.

(2011a): "The ECB's Non-Standard Measures - Impact and Phasing-Out," ECB Monthly Bulletin, July 2011, pp. 55-69.

(2011b): The Implementation of Monetary Policy in the Euro Area: General Documentation on Eurosytem Monetary Policy Instruments and Procecdures, February 2011. 
Ewerhart, C. (2002): "A Model of the Eurosystem's Operational Framework for Monetary Policy Implementation," European Central Bank Working Paper No. 197.

Ewerhart, C., N. Cassola, and N. Valla (2010): "Declining Valuations and Equilibrium Bidding in Central Bank Refinancing Operations," International Journal of Industrial Organization, 28, 30-43.

(2012): "Overbidding in Fixed Rate Tenders: The Role of Exposure Risk," Journal of Banking and Finance, 36, 539-549.

Fecht, F., K. G. Nyborg, and J. Rocholl (2010): "The Price of Liquidity: Bank Characteristics and Market Conditions," Swiss Finance Institute Research Paper No. $10-20$.

Freixas, X., and C. Holthausen (2005): "Interbank market integration under asymmetric information," Review of Financial Studies, 18(2), 459-490.

Freixas, X., And J. Jorge (2008): "The Role of Interbank Markets in Monetary Policy: A Model with Rationing," Journal of Money, Credit and Banking, 40(6), 1151-1176.

Furfine, C. H. (2000): "Interbank Payments and the Daily Federal Funds Rate," Journal of Monetary Economics, 46, 535-553.

González-PÁramo, J. M. (2009): "Financial Market Failures and Public Policies: A Central Banker's Perspective on the Global Financial Crisis," Speech at the XVI Meeting of Public Economics in Granada, 6 February 2009. Available at: http://www.ecb.de/press/key/date/2009/html/index.en.html.

(2010): "The European Central Bank and the Policy of Enhanced Credit Support," Speech at a conference organized by Cámara de Comercio de Málaga and the University of Málaga on 18 June 2010.. Available at: http://www.ecb.de/press/key/date/2010/html/index.en.html.

Hamilton, J. D. (1996): "The Daily Market for Federal Funds," Journal of Political Economy, 104, 26-56.

Hassler, U., And D. Nautz (2008): "On the Persistence of the Eonia Spread," Economics Letters, 101, 184-187.

Heider, F., M. Hoerova, and C. Holthausen (2009): "Liquidity Hoarding and Interbank Market Spreads: The Role of Counterparty Risk," European Central Bank Working Paper No. 1126.

Ho, T. S. Y., And A. Saunders (1985): "A Micro Model of the Federal Funds Rate," Journal of Finance, 40, 977-986.

Leland, H. E., And D. H. Pyle (1977): "Information Asymmetries, Financial Structure, and Financial Intermediation," Journal of Finance, 32, 371-387.

Lenza, M., H. Pill, And L. Reichlin (2010): "Monetary Policy in Exceptional Times," Economic Policy, 25, 295-339.

Linzert, T., D. Nautz, and J. Breitung (2006): "Bidder Behavior in Central Bank Repo Auctions: Evidence from the Bundesbank," Journal of International Financial Markets, Institutions and Money, 16, 215-230. 
Linzert, T., And S. Schmidt (2011): "What explains the Spread between the Euro Overnight Rate and the ECB's Policy Rate?," International Journal of Finance and Economic, 16, 275-289.

Nautz, D., And J. Oechssler (2003): "The Repo Auctions of the European Central Bank and the Vanishing Quota Puzzle," Scandinavian Journal of Economics, 105, 207220 .

(2006): "Overbidding in Fixed Rate Tenders - an Empirical Assessment of Alternative Explanations," European Economic Review, 50, 631-646.

Neyer, U. (2009): "Interest on Reserves and the Flexibility of Monetary Policy in the Euro Area," Scandinavian Journal of Economics, 111, 417-438.

Neyer, U., AND J. Wiemers (2004): "The Influence of a Heterogeneous Banking Sector on the Interbank Market Rate in the Euro Area," Swiss Journal of Economics and Statistics, 140, 395-428.

Nyborg, K. G., U. Bindseil, and I. A. Strebulaev (2002): "Bidding and Performance in Repo Auctions: Evidence from ECB Open Market Operations," European Central Bank Working Paper No. 157.

NyborG, K. G., and I. A. Strebulaev (2001): "Collateral and Short Squeezing of Liquidity in Fixed Rate Tenders," Journal of International Money and Finance, 20, 769-792. ies, $17,545-580$.

Ross, S. A. (1977): "The Determination of Financial Structure: The Incentive-Signalling Approach," The Bell Journal of Economics, 8(1), 23-40.

Shino, J. (2012): "A Positive Theory of Fixed-rate Funds-supplying Operations in an Accommodative Financial Environment," Journal of International Money and Finance, http://dx.doi.org/10.1016/j.jimonfin.2012.05.026.

Smaghi, L. B. (2008): "Restarting a Market: The Case of the Interbank Market," Speech at the ECB Conference on Global Financial Linkages, Transmission of Shocks and Asset Prices in Frankurt, 1 December 2008. Available at: http://www.ecb.de/press/key/date/2008/html/sp081201.en.html.

(2011): "One size fits all?," Speech at the 16th Annual Conference of the GermanBritish Forum - The Eropean Central Bank in a Global Perspective - Central Banking and the Challenge of Rising Inflation - in London, 26 May 2011. Available at: http://www.ecb.de/press/key/date/2011/html/sp1105261.en.html.

SoAres, C., And P. M. M. Rodrigues (2010): "Determinants of the EONIA Spread and the Financial Turmoil of 2007-2009," Banco de Portugal Economic Bulletin.

Stiglitz, J. E., And A. Weiss (1981): "Credit Rationing in Markets with Imperfect Information," American Economic Review, 71, 393-410.

Trichet, J. C. (2009): "The Crisis and its Lessons," BIS Review No 125, (125), 8-18. 